\title{
CONSIDERAÇÕES ACERCA DO ÊTHOS GERMÂNICO NA GERMANIA DE TÁCITO
}

\author{
Henrique Verri Fiebig* \\ Universidade de São Paulo
}

\begin{abstract}
Resumo. Propõe-se neste estudo uma reflexão acerca do êthos das populações germânicas na primeira seção da Germania de Públio Cornélio Tácito. Considerando que êthos pode ser entendido como uma construção que reúne elementos tanto intradiscursivos quanto extradiscursivos, sugere-se que a construção deste êthos germânico obedece tanto aos lugares-comuns do gênero epidítico da retórica, os quais podem ser relacionados aos topoi do gênero etnográfico identificados pelos estudiosos modernos, quanto à expectativa de uma recepção condicionada aos estereótipos correntes acerca do bárbaro do Norte.
\end{abstract}

Palavras-chave. Historiografia Antiga; Etnografia Antiga; Gênero Epidítico.

D.O.I. 10.11606/issn.2358-3150.v19i2p90-98

Nesse ARtigo, teceremos algumas Considerações SObre como o ÊTHOS das populações germânicas é construído pelo historiador Públio Cornélio Tácito (c. 56 - c. 117 d.C.) naquela que é considerada pelos estudiosos modernos $^{1}$ a primeira seção - que compreende trecho dos parágrafos I ao XXVII - de seu breve trabalho, possivelmente escrito em 98 d.C., intitulado De origine et situ germanorum ou, como é mais comumente conhecido, Germania.

Antes de dar início ao nosso estudo, é necessário sublinhar que entendemos êthos como uma construção intra e extradiscursiva de personagens fictícios ou não. Os elementos intradiscursivos são aqueles que são próprios ao discurso, como, por exemplo, a utilização dos preceitos conceituados pelos manuais de retórica antiga; já os elementos extradiscursivos consistem na expectativa da recepção, isto é, dos leitores e ouvintes do texto, e das convenções que são resultado desta recepção, as quais podemos definir como estereótipos. ${ }^{2}$

\footnotetext{
* Mestre em Letras Clássicas pela Universidade de São Paulo (2014).

" Artigo recebido em 05.set.2016 e aceito para publicação em 25.out.2016.

${ }^{1}$ Ver, por exemplo, Rives 1990, 49.

${ }^{2}$ Ver Dibbern 2013, 50-62.
} 
Deste modo, acreditamos que o êthos dos povos germânicos tanto é construído retoricamente como atende a uma determinada expectativa da recepção do texto. Veremos, pois, que este êthos é constituído a partir de preceitos que são próprios ao gênero epidítico ou demonstrativo da retórica, tal como é prescrito em tratados gregos e latinos sobre oratória, e que se relaciona tanto à idéia geral e estereotipada sobre os bárbaros do Norte, que era lugar-comum na região do Mediterrâneo, quanto à situação política do Império no período de Tácito.

Sabe-se que o gênero epidítico ou demonstrativo trata do elogio ou da censura de algo ou alguém. Este elogio ou esta censura são feitos através de lugares-comuns também retoricamente condicionados. Lemos no tratado latino Rhetorica ad Herennium 3.10:

Passemos agora ao gênero demonstrativo de causa. Já que esta causa é dividida em elogio e vitupério, com os tópicos a partir dos quais construiríamos o elogio, por seus contrários, será apresentado o vitupério. O elogio pode, pois, ser das coisas externas [rerum externarum], do corpo [corporis] e do ânimo [animi].

Coisas externas são aquelas que podem ocorrer, por acaso ou fortuna, favorável ou adversa: ascendência, educação, riqueza, poder, glória, cidadania, amizades, e o que é desta espécie e o seu contrário. Coisas do corpo são aquelas que a natureza atribuiu ao corpo, convenientes ou inconvenientes: rapidez, força, beleza, e o que é seu contrário. Coisas do ânimo são aquelas que consistem de nosso julgamento e pensamento: prudência, justiça, coragem, moderação, e o que é seu contrário. ${ }^{3}$

Outros topoi epidídicos dignos de serem mencionados, que aparecem em outros tratados retóricos latinos, como, por exemplo, aqueles de Cícero e Quintiliano, são: nome, natureza, vida, hábito, afetos, feitos, ascendência, nação, pátria, corpo, fortuna, entre outros. ${ }^{4}$

Ora, é possível encontrar, na composição do êthos dos germanos, uma caracterização que certamente remete muito aos lugares-comuns epidíticos acima mencionados e que se dividem nas três categorias, a saber, mais uma vez, em coisas externas, do corpo e do ânimo.

Sobre as coisas externas, ou res externae, podemos encontrar no texto a seguinte passagem acerca da ascendência e origem dos germanos:

Celebram em canções antigas, que são o único gênero de registro e anais entre eles, o deus Tuistão, nascido da terra. A ele atribuem filho, Mano, origem da gente, e três filhos a Mano, seus fundadores, de cujos nomes chamam-se ingevões próximos ao Oceano, herminões ao centro, istevões os restantes. [II, 3 $]^{5}$

\footnotetext{
3 Tradução nossa.

${ }^{4}$ Hansen 2006, 95.

${ }^{5}$ A tradução dos trechos da Germania é nossa.
} 


\section{Temos também trechos acerca de seus nomes:}

Alguns afirmam, como que por permissão da antiguidade, ao deus mais descendentes e mais denominações de gente - marsos, gambrívios, suevos, vandílios - e que tais são nomes verdadeiros e antigos; 5. ademais, que o termo Germânia é recente e há pouco aplicado, porquanto os primeiros que atravessaram o Reno expulsaram os galos e chamam-se agora tungros, antes germanos [...]. [II, 3-4]

\section{E suas riquezas:}

Prata e ouro negaram-lhes os deuses - se por favor ou irados, não o sei. Todavia, não afirmaria que nenhuma veia da Germânia engendra prata ou ouro: quem, de fato, explorou-a? 4. Não são influenciados por sua posse e uso igualmente. Vê-se entre eles aparatos de prata, dados como presente aos embaixadores e comandantes deles, a não outro baixo preço que o quê se molda do chão. [V, 3-4]

Quanto a seus hábitos e costumes, os quais podemos também atribuir às coisas externas, encontramos muitos exemplos por todo o texto. Tácito nos fornece um relato sobre seu sistema político:

Tomam reis consoante nobreza, generais consoante valor; nem mesmo aos reis poder ilimitado e irrestrito [...]. [VII, 1]

\section{Sua religião:}

Dentre os deuses, cultuam sobretudo Mercúrio, ao qual, em determinados dias, têm por justo sacrificar também vítimas humanas. Aplacam Hércules e Marte com animais permitidos. [IX, 1]

\section{Seus costumes matrimoniais:}

Entretanto, matrimônio lá é rigoroso, e nenhum aspecto de seus costumes elogiarse-ia mais; pois são praticamente os únicos, dentre os bárbaros, contentes com uma esposa, excetuados mui poucos que, não por libido mas por nobreza, são cobiçados por muitos casamentos. 2. Dote não oferece esposa ao marido, mas à esposa marido. Interpõem-se pais e parentes e apreciam os presentes, presentes requeridos não para mimos femininos, nem com eles se adorna a nova noiva, mas bois e cavalo bridado e escudo com frâmea e gládio. [XVIII, 1-2]

De fato, exemplos de seus hábitos e costumes poderiam ser elencados à exaustão. Passemos, todavia, aos excertos que tratam das coisas do corpo, ou res corpori. Encontramos os seguintes exemplos sobre sua aparência e força:

[...] daí também a aparência dos corpos, tão quanto em tamanho número de pessoas, a mesma em todos: olhos ferozes e azuis, cabeleira louro-avermelhada, corpos grandes e robustos somente ao ataque; 3 . ao labor e exercício tolerância outra, e pouco habituaram-se a suportar sede e calor; frio e fome, sim, por clima ou solo. [IV, 2-3] 
Há ainda trechos sobre as suas vestimentas:

Vestimenta de todos, sago preso com broche ou, se este falta, osso; por outro lado, passam dias inteiros junto da lareira e fogo, descobertos. Os mais ricos distinguem-se não por veste larga como a do sármata e parto, mas justa e moldando cada membro. [XVII, 1]

Relatos que dizem respeito às coisas do ânimo, ou res animi, são também copiosos na Germania. Lemos sobre o amor dos germanos por sua liberdade:

[...] sem dúvida mais enérgica que o reino de Arsace é a liberdade dos germanos. [XXXVII, 3]

Mas também que, desta liberdade, vem o vício, assim:

Da liberdade este vício, pois não se reúnem ao mesmo tempo nem como ordenados, mas consome-se dois ou três dias pela demora dos participantes. [XI, 3]

Tácito menciona, como vimos pouco acima, que os germanos são um povo moderado quanto às mulheres e o matrimônio:

Entretanto, matrimônio lá é rigoroso, e nenhum aspecto de seus costumes elogiarse-ia mais; pois são praticamente os únicos, dentre os bárbaros, contentes com uma esposa [...]. [XVIII, 1]

Mas que, em se tratando de bebida, a situação muda um pouco:

Afastam a fome sem aparato, sem condimentos; contra a sede, temperança outra. Se fores complacente com sua embriaguez, fornecendo o quanto desejam, serão vencidos mais facilmente pelos vícios que por armas. [XXIII, 1-2]

Sua coragem, e grande estima por ela, são admiráveis:

Tomam reis consoante nobreza, generais consoante valor; nem mesmo aos reis poder ilimitado e irrestrito, e os generais comandam por exemplo mais que autoridade, por admiração, se dispostos, se visíveis, se lideram ante a linha. [VII, 1]

Mas tal coragem pode levar a um gosto excessivo pelo conflito:

Nem a arar terra nem a expectar colheita anual se persuadi-los-ia tão facilmente quanto a provocar inimigo e ganhar feridas; parece-lhes, sim, indolência e preguiça adquirir com suor o que se pode obter com sangue. [XIV, 4]

Ora, acreditamos que os exemplos dados acima sejam suficientes para demonstrar que a construção do êthos das populações germânicas tem como base topoi epidíticos que são retoricamente prescritos, como visto no excerto da Rhetorica ad Herennium. É interessante mencionar aqui que es- 
tes topoi epidíticos são muito próximos àqueles lugares-comuns identificados pelos estudiosos modernos como próprios ao gênero etnográfico, ${ }^{6}$ gênero ao qual pertenceria a Germania, de acordo com a maioria de seus comentadores modernos. ${ }^{7}$ Ora, considerando que a existência de um gênero etnográfico neste período é discutível, ${ }^{8}$ seria interessante pensar se as descrições de povos estrangeiros não são, entre gregos e romanos, governadas por estes topoi epidíticos, ao invés dos lugares-comuns etnográficos identificados pelos scholars modernos. Deixaremos, todavia, esta discussão para outra oportunidade.

Até agora, vimos como o êthos dos povos germânicos é retoricamente construído por Tácito a partir de procedimentos prescritos pelo gênero epidítico. Nas linhas a seguir, tentaremos delinear os traços fundamentais deste caráter germânico.

Lund $^{9}$ atribui quatro características gerais fundamentais aos germanos a partir da descrição de Tácito, que são: simplicitas, ira/iracundia, inertia e libertas. Sua simplicidade pode ser constatada, por exemplo, no modo como comerciam, em suas técnicas de construção ou em suas vestimentas:

[...] os [germanos] do interior empregam, de modo mais simples e antigo, a permutação de bens. $[\mathrm{V}, 4]$

Nem mesmo há o uso de cantarias ou tijolos entre eles: para tudo empregam madeira, informe e sem beleza ou deleite. [XVI, 3]

Usam também peles de animais, os próximos à margem negligentemente, os do interior mais cuidadosamente, já que, para eles, por comércio nenhum adorno. [XVII, 2]

Sua ira faz-se ver no modo como matam seus escravos não por disciplina, mas por ímpeto:

Vergastar servo e coagi-lo com grilhões e trabalho, raro: costumam matá-los, não por disciplina ou severidade, mas por ímpeto e ira, tal como inimigo, exceto que é impune. $[\mathrm{XXV}, 2]$

\footnotetext{
${ }^{6}$ Os lugares-comuns etnográficos são, de acordo com K. Trüdinger 1918: a) o da origo (autoctonia, miscigenação e genealogia); b) definição e derivação do nome dos povos; c) número de povos; d) aparência física; e) armamento e práticas de guerra; f) vestuário; g) habitação; h) modo de vida, alimentação, bebida, costumes ligados ao comer e beber; i) regime (organização política); j) deuses; k) sacrifícios; 1) divinação; m) juramentos e alianças; n) matrimônio e vida do homem e da mulher; o) procedimentos funerários; p) caráter do povo; r) indagação sobre a singularidade dos costumes; s) paradoxografia; t) teorias climáticas.

${ }^{7}$ Ver, por exemplo, os estudos de Perret 1949; Lund 1989; Rives 1999.

${ }^{8}$ Ver Marincola 1999.

${ }^{9}$ Lund 1999, 62-72.
} 


\section{Observamos sua indolência e predileção por ela:}

[...] eles mesmos vadiam, extraordinária sua inconstância de temperamento, visto que ao mesmo tempo os homens assim amam a indolência e odeiam a quietude. [XV, 1]

Por fim, vê-se a importância que tem a liberdade para eles em seu medo do cativeiro e na dificuldade militar que impuseram a Roma:

Transmite-se que certas linhas já desbaratadas e vacilantes foram restituídas pelas mulheres através da constância das súplicas e interposição dos peitos, e mostrando próximo o cativeiro, o qual temem muito mais inquietamente em nome de suas mulheres [...]. [VIII, 1]

Através de espaço tão longo de tempo, muitas as perdas de cada lado. Nem samnitas, nem fenícios, nem Hispânia ou Gália, nem mesmo partas admoestaram com mais freqüência: sem dúvida mais enérgica que o reino de Arsace é a liberdade dos germanos. [XXXVII, 3]

Evidentemente, estas características mencionadas por Lund são constituintes do êthos germânico, como pudemos ver; não obstante, acreditamos que seja possível observar este êthos ainda mais minuciosamente.

Os germanos são descritos por Tácito como um povo autóctone e homogêneo em aspecto:

Os próprios germanos são autóctones, creio, e pouco misturados por imigrações de outras gentes e hospedagens [...] [II, 1]

[...] daí também a aparência dos corpos, tão quanto em tamanho número de pessoas, a mesma em todos: olhos ferozes e azuis, cabeleira louro-avermelhada, corpos grandes e robustos somente ao ataque [...]. [IV, 2]

Eles são ainda supersticiosos:

Observam, como os que mais o fazem, auspícios e sortes. [X, I]

\section{Corajosos:}

Quando presente à linha, torpe ao chefe ser superado em valor, torpe ao companheiro não igualar seu valor ao do chefe. Além disso, infâmia por toda vida e opróbrio ter se retirado da linha, sobrevivente ao seu chefe; defendê-lo, protegê-lo, destinar seus valorosos feitos à glória dele é o principal juramento: chefes lutam pela vitória, companheiros lutam pelo chefe. [XIV, I]

\section{Belicosos:}

Caso a tribo em que cresceram entorpeça por longa paz e ócio, muitos dos jovens nobres buscam além àquelas nações que então empenham alguma guerra, porque re- 
pouso é ingrato à gente e distinguem-se mais facilmente em meio a riscos, e não se mantém grande companhia senão por força e guerra. [XVI, 2]

\section{Inconstantes em temperamento:}

[...] eles mesmos vadiam, extraordinária sua inconstância de temperamento, visto que ao mesmo tempo os homens assim amam a indolência e odeiam a quietude. [XV, 1]

Morais e incorruptos em certos costumes:

Vivem, pois, em cercada pudicícia, corrompidas por nenhum encantamento de espetáculos, nenhuma incitação de convívios. Os segredos dos bilhetes ignoram os homens e do mesmo modo as mulheres. [XIX, 1]

Lá ninguém ri dos vícios, nem se denomina última moda corromper e ser corrompido. [XIX, 3]

Embora, às vezes, pouco sábios e imprudentes:

Gente nem astuta nem prudente, lá desvela os segredos do peito, por licença da ocasião; o caráter de todos, pois, exposto e desnudo. [XX, 4]

E também excessivos, como se vê em sua relação com jogo:

Jogo de azar, é de se admirar, praticam sóbrios entre coisas sérias, com tamanha temeridade no ganhar ou perder que, quando desperdiçaram tudo, se medem às expensas de sua liberdade e de seu corpo em último e derradeiro lance. O perdedor segue para a servidão voluntária; embora mais jovem, embora mais robusto, deixa-se amarrar e vender. Esta é a obstinação na questão viciosa; os próprios chamam-na fidelidade. [XXIV, 3-4]

Uma característica enfatizada na obra é seu senso de coletividade, por assim dizer: todos decidem em assembléia sobre qualquer assunto importante:

Das matérias menores deliberam os chefes, das maiores, todos, embora de modo que também estas, cujo juízo dá-se entre a plebe, sejam pré-tratadas entre os comandantes. $[\mathrm{XI}, 1]$

É possível afirmar, portanto, que o êthos germânico geral, ou seja, aquele da primeira parte do texto de Tácito, é caracterizado pela simplicidade, ira, indolência, amor à liberdade, homogeneidade física, superstição, coragem, belicosidade, inconstância, moralidade, imprudência, excesso e senso de coletividade.

Ora, como sabemos, o gênero epidítico trata do elogio e da censura. Considerando esta caracterização dos povos germânicos, é possível afirmar que seu êthos possui tanto aspectos positivos quanto negativos, sendo este 
êthos, portanto, digno tanto de encômio quanto de vitupério. Dignos de elogio são sua simplicidade, coragem, castidade, seu amor pela liberdade, suas decisões coletivas; dignos de censura, sua indolência, ira, inconstância de temperamento, seus excessos na bebida e no jogo.

Este tom misto é resultado, supomos, de elementos extradiscursivos que também trabalham na construção deste êthos. Estes elementos extradiscursivos são: as expectativas da recepção e as convenções que resultam disto, neste caso, os estereótipos comumente associados à imagem do bárbaro do Norte, além do contexto político romano nos tempos de Tácito.

Dench $^{10}$ identifica os citas como os ancestrais da representação dos bárbaros setentrionais. Este povo era usualmente descrito, ao menos desde o século IV a.C., como simples, autossuficiente, moral, frugal, nada ganancioso, casto e governado mais por bons hábitos que por leis. ${ }^{11}$ Os celtas teriam sido os segundos nessa linha, sendo frequentemente caracterizados por sua temeridade, bravura irracional e impulsividade. ${ }^{12}$ As similaridades entre estas caracterizações de citas e celtas, de um lado, e dos germanos de Tácito, de outro, nos parecem claras. Sendo assim, podemos afirmar que o estereótipo do bárbaro setentrional tem papel na descrição taciteana das populações germânicas.

Ademais, a relevância dada por Tácito a sua simplicidade, liberdade e senso de coletividade pode ser explicada por seu pensamento político, assim como pelo contexto político e moral de seu tempo. Sabe-se que, na Germania, há uma comparação implícita entre os costumes romanos e germânicos. Por exemplo, quando ele faz um relato sobre a castidade dos jovens germanos ou sobre a frugalidade de seus hábitos, há uma crítica subjacente à conduta impudente que predominava na urbs de então; quando ele nos fala sobre quão enérgica é sua liberdade ou sobre como eles deliberam coletivamente acerca de seus assuntos em assembleia, é impossível não lembrar que Tácito, um admirador da velha República, vivia então em um principado que era propenso à tirania, e que a Germania foi escrita, possivelmente, apenas dois anos após a morte do imperador Domiciano.

Concluindo: vimos que o êthos das populações germânicas na primeira seção da Germania de Tácito é constituído tanto por elementos intradiscursivos como extradiscursivos. Tácito caracteriza seus germanos retoricamente, lançando mão de topoi próprios ao gênero epidítico, topoi estes relacionados aos lugares-comuns etnográficos identificados pelos pesquisadores modernos. Ademais, vimos que a construção deste êthos é influenciada pelos este-

\footnotetext{
${ }^{10}$ Dench 2005, 49.

${ }^{11}$ Rives 1999, 19-20.

12 Rives 1999, 20.
} 
reótipos do bárbaro setentrional que eram correntes no momento da produção do texto e pelo contexto moral e político do tempo em que Tácito vivia.

\section{REFERÊNCIAS}

Dench, E. 2010. Romulus' Asylum: Roman Identities from the Age of Alexander to the Age of Hadrian. New York: Oxford University Press.

Dibbern, C. H. 2013. O êthos de Aníbal em Tito Livio e Cornélio Nepos: imagines. Dissertação de Mestrado. Universidade de São Paulo.

Hansen, J. A. 2006. "Categorias epidíticas da ekphrasis." Revista USP 71: 85-105.

Hutton, M. 1970. Agricola, Germania, Dialogus. Cambridge and London: Harvard University Press.

Jacoby, F. 1956. "Über die Entwicklung der grichischen Historiographie und den Plan einer neuen Sammlung der griechschen Historikerfragmente". In Abhandlungen zur griechischen Geschichtschreibung. Leiden: E. J. Brill.

Lund, A. A. 1988. Tacitus: Germania. Heidelberg: Carl Winter.

Marincola, J. 1999. "Greco-Roman Historiography". In The Limits of Historiography, edited by C. S. Kraus. Leiden, Boston, Köln: Brill.

Martins, P. 2012. Imagens e Poder: Considerações sobre a Representação de Otávio Augusto. São Paulo: Edusp.

Perret, J. 1949. Tacite: La Germanie. Paris: Les Belles Lettres.

Rives, J. B. 1999. Tacitus: Germania. Oxford: Clarendon Press.

Rodolpho, M. 2012. Écfrase e Evidência nas Letras Latinas: Doutrina e Práxis. São Paulo: Humanitas.

Trüdinger, K. 1918. Studien zur Geschichte der grieschisch-römischen Ethlographie. Basel: Buchdruckrei Emil Birkhäuser.

\section{$*$}

Title. Observations on the Germanic êthos in Tacitus' Germania.

Abstract. This paper proposes a reflection on the êthos of Germanic peoples in the first section of Tacitus' Germania. Considering that êthos can be understood as a construct based both on intra-discursive and extra-discursive elements, it suggests the construct of the Germanic êthos is regulated by common-places of the epideictic genre of rhetoric - which are related to the ethnographic topoi identified by modern scholars - as well as by the expectations of a reception conditioned to the stereotypes concerning the Northern barbarians.

Keywords: Ancient Historiography; Ancient Ethnography; Epideictic Genre. 